\title{
Ionospheric variations before some large earthquakes over Sumatra
}

\author{
A. M. Hasbi ${ }^{1,2}$, M. A. Mohd Ali ${ }^{1,2}$, and N. Misran ${ }^{1,2}$ \\ ${ }^{1}$ Department of Electrical, Electronic and Systems Engineering, Faculty of Engineering and Built Environment, University \\ Kebangsaan Malaysia, Bangi, Selangor, Malaysia \\ ${ }^{2}$ Institute of Space Science (ANGKASA), University Kebangsaan Malaysia, Bangi, Selangor, Malaysia
}

Received: 27 May 2010 - Revised: 17 January 2011 - Accepted: 17 January 2011 - Published: 22 February 2011

\begin{abstract}
The paper investigates the ionospheric variations before some large earthquakes that occurred during 20042007 in Sumatra using GPS and CHAMP data. The TEC shows the occurrence of positive and negative anomalies detected within a few hours to 6 days before the earthquakes. These anomalies mostly occur during the daytime hours between 4 and 17 LT. The TEC anomalies are mostly consistent with the CHAMP satellite electron density data. The electron density analysis over the 28 March 2005 earthquake epicenter shows that an equatorial anomaly modification took place a few days before the event. The modification took shape in the form of crest amplification during the daytime. The comparison between the TEC and electron density measurements during very quiet geomagnetic conditions is shown to be a useful indicator of a forthcoming earthquake.
\end{abstract}

\section{Introduction}

Earlier research on ionospheric precursors of earthquakes began about three decades ago (Antsilevich, 1971; Datchenko et al., 1972; Gokhberg et al., 1983a, b). Antsilevich (1971) observed a local increase in the ionospheric foE parameter above the epicenter before the 1966 Tashkent earthquake using ground-based ionosonde stations. One year later, Datchenko et al. (1972) also observed anomalous ionospheric electron variations before the same earthquake and attributed them to the redistribution of electric charges within the Earth-atmosphere system. Gokhberg et al. (1983a) analyzed the magnetic measurements onboard the OGO-6 satellite over epicenters of strong earthquakes in Japan. They found anomalous ELF emissions of short periods that appeared in the range of $10 \mathrm{~Hz}-1 \mathrm{kHz}$ a few hours before 3 of

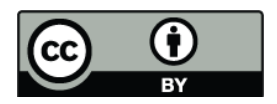

Correspondence to: A. M. Hasbi (alina.ukm@gmail.com) the 6 events studied. Gokhberg et al. (1983b) found a local trough of $20 \%$ in the plasma density in both AE-C and ISI-2 satellite measurements above the epicenters of midlatitude earthquakes. Recently, there has been a widespread of research devoted to the study of lithosphere-atmosphereionosphere coupling in search of short-term earthquake precursors. Many efforts have been made to improve the overall knowledge surrounding earthquakes, from the physical mechanism to the main features of seismo-ionospheric phenomena (Gokhberg et al., 1995; Shalimov and Gokhberg, 1998; Molchanov et al., 2004; Pulinets and Boyarchuk, 2004; Hayakawa, 2006; Ondoh, 2009).

The advent of the Global Positioning System (GPS) sensing technology opens a new era in remote sensing of the ionosphere. GPS data provides exciting prospects in seismology including detecting, imaging and analyzing signals in regions of seismic activity. More recent studies have reported pre-earthquake ionospheric anomalies using groundbased GPS stations (Liu et al., 2004, 2008; Zakharenkova et al., 2007; Saroso et al., 2008; Yiyan et al., 2009). Some of these studies have also highlighted that the disturbance area prior to large earthquakes extends over a distance of $1500 \mathrm{~km}$ in latitude and $4000 \mathrm{~km}$ in longitude. Liu et al. (2004) performed a statistical analysis on $20 M \geq 6.0$ earthquakes in the Taiwan region using GPS TEC data and found that $80 \%$ of pre-earthquake ionospheric anomalies occurred at about 18:00-22:00 LT during 1-5 days before the events. More recently, Liu et al. (2008) examined the TEC obtained from 8 GPS receivers scattered in Taiwan before the 2006 Pingtung earthquakes and found a decrease of about 7 TECU (30\% from the reference value) and with duration of $4.5 \mathrm{~h}$. Yiyan et al. (2009) reported increases as well as decreases of $40-70 \%$ in the TEC measurements during the afternoon hours of 13:00-18:00 LT about 3 days prior to the 2008, M7.9 Wenchuan earthquake in China. Using the GPS TEC map, they also found that these anomalies moved from the

Published by Copernicus Publications on behalf of the European Geosciences Union. 
Table 1. The occurrence time, geographic coordinates, depth, magnitude and earthquake preparation radius of large earthquake events in Sumatra (http://earthquake.usgs.gov).

\begin{tabular}{|c|c|c|c|c|c|c|c|c|}
\hline \multirow{2}{*}{ Event } & \multirow{2}{*}{ Place } & \multirow{2}{*}{ Date } & \multirow{2}{*}{$\begin{array}{c}\text { Time of } \\
\text { earthquake } \\
\text { (UT) }\end{array}$} & \multicolumn{2}{|c|}{ Geographic } & \multirow{2}{*}{$\begin{array}{c}\text { Depth } \\
(\mathrm{km})\end{array}$} & \multirow{2}{*}{$M$} & \multirow{2}{*}{$\begin{array}{c}\text { Earthquake } \\
\text { preparation } \\
\text { radius, } R(\mathrm{~km})\end{array}$} \\
\hline & & & & Lat. $\left({ }^{\circ}\right)$ & Lon. $\left({ }^{\circ}\right)$ & & & \\
\hline 1 & North Sumatra & 26 Decemer 2004 & 00:58 & $3.32^{\circ} \mathrm{N}$ & $95.85^{\circ} \mathrm{E}$ & 30 & 9.3 & 9977 \\
\hline 2 & North Sumatra & 28 March 2005 & $16: 09$ & $2.08^{\circ} \mathrm{N}$ & $97.01^{\circ} \mathrm{E}$ & 30 & 8.6 & 4988 \\
\hline 3 & South Sumatra & 12 September 2007 & $11: 10$ & $4.52^{\circ} \mathrm{S}$ & $101.37^{\circ} \mathrm{E}$ & 34 & 8.5 & 4518 \\
\hline 4 & Kepulauan Mentawai & 12 September 2007 & $23: 49$ & $2.51^{\circ} \mathrm{S}$ & $100.91^{\circ} \mathrm{E}$ & 30 & 7.9 & 2495 \\
\hline
\end{tabular}

equatorial northern crest towards the equator a few days before the earthquake.

Satellite-based measurements were also investigated before earthquakes (Trigunait et al., 2004; Gousheva et al., 2006; Sarkar et al., 2007; Hsiao et al., 2009; Akhoondzadeh et al., 2010). Gousheva et al. (2006) examined the ion density and quasi-electric field data onboard the INTERCOSMOSBULGARIA-1300 satellite and found disturbances in both measurements a few minutes before some of the strong earthquakes. Using DEMETER satellite measurements near the epicenters of three strong mid-latitude earthquakes, Sarkar et al. (2007) reported significant fluctuations in the electron and ion density data a few days before the events. Akhoondzadeh et al. (2010) further demonstrated the efficiency of both ground-based GPS TEC and DEMETER satellite electron density measurements to detect pre-earthquake electron density anomalies.

The main physical mechanism of these seismoionospheric anomalies is well explained by Pulinets and Boyarchuk (2004) in terms of upward propagation of the seismogenic electric field generated within the earthquake preparation zone into the ionosphere a few days before earthquakes. This seismogenic electric field then influences the plasma density in the ionosphere. Other coupling mechanisms that explain the appearances of seismo-ionospheric anomalies are acoustic gravity waves, dirty plasma diffusion and the emissions of electromagnetic waves (see papers of Pulinets et al., 1994; Molchanov and Hayakawa, 1998; Rapoport et al., 2004; Hayakawa, 2006). Although these mechanisms are not fully understood, it is assumed that these anomalies first appear near the Earth's surface and then penetrate to higher altitudes.

There has been great interest in the research of zonal electric field influence caused by earthquake preparation processes on the equatorial ionosphere. The equatorial anomaly (EA) is a regular phenomenon of the ionosphere, which manifests itself as a deep electron concentration, $\mathrm{N}_{e}$ trough near the geomagnetic equator with two peaks at $15-20^{\circ}$ north and south of it. During quiet magnetic conditions, the EA structure in the latitudinal distribution of $\mathrm{N}_{e}$ occurs in the mid-morning hours, reaches its maximum development in the afternoon and then gradually disappears in the evening and nighttime. At night, the EA crests shift equatorward and the maximum $\mathrm{N}_{e}$ at the geomagnetic equator is restored. It is well known that the EA is very sensitive to any changes in electric fields of various origins. Recently, research has been done to study the EA modification structure prior to low-latitude and equatorial earthquakes (Liu et al., 2002; Pulinets and Lagen'ka, 2002; Zakharenkova et al., 2006, 2008). The main features of the modification are manifested in the daytime EA amplification and crest's disappearance as well as the nighttime double-crest structure with a trough near the epicenter.

This paper aims at investigating the ionospheric perturbations prior to 4 earthquakes with a magnitude of $M \geq 7.0$ over Sumatra during the period from 2004-2007 using GPS TEC measurements surrounding the epicenters. It also attempts to study the behavior of the EA structure before equatorial earthquakes using ground and satellite based measurements. The occurrence time, geographic coordinates, depth, magnitude and the radius of the earthquake preparation zone of these events are summarized in Table 1 . In this work, the radius of the earthquake preparation zone for each earthquake is estimated using the Dobrovolsky formula: $R=10^{0.43 M}$, where $R$ is the radius of the earthquake preparation zone $(\mathrm{km})$ and $M$ is the earthquake magnitude on the Richter scale (Dobrovolsky et al., 1979). Figure 1 presents the locations of the earthquake epicenters (star and circle) and GPS receiver stations (triangle), in geographic coordinates. Table 2 presents the geographic coordinates of the GPS receiver stations and their distances from the epicenters.

\section{Data processing and measurement techniques}

GPS data obtained from 7 sets of dual frequency permanent GPS receiver stations located within distances of up to $2300 \mathrm{~km}$ from the earthquake epicenters in Sumatra are collected to examine the ionospheric disturbances prior to large earthquakes. These stations are Arau (ARAU), University Sains Malaysia Penang (USMP), University Teknologi Malaysia Johor (UTMJ), Nanyang Technology University of Singapore (NTUS), Pulai Sikuai (PSKI), Bulasat (BSAT) and Cocos Island (COCO). Among these, the former 3 belong 
Table 2. The geographic coordinates of the GPS stations and their distances from the epicenters.

\begin{tabular}{lllllll}
\hline & & & \multicolumn{3}{l}{ Distance from epicenter $(\mathrm{km})$} \\
\cline { 4 - 7 } GPS station & Geographic coordinate & Country & \multicolumn{2}{c}{ Event } & & \\
\cline { 4 - 7 } & & & 1 & 2 & 3 & 4 \\
\hline ARAU & $6.50^{\circ} \mathrm{N}, 100.28^{\circ} \mathrm{E}$ & Malaysia & 606 & 602 & $*$ & $*$ \\
USMP & $5.36^{\circ} \mathrm{N}, 100.30^{\circ} \mathrm{E}$ & Malaysia & 543 & $*$ & $*$ & $*$ \\
UTMJ & $1.56^{\circ} \mathrm{N}, 103.64^{\circ} \mathrm{E}$ & Malaysia & 887 & $*$ & $*$ & $*$ \\
NTUS & $1.36^{\circ} \mathrm{N}, 103.69^{\circ} \mathrm{E}$ & Singapore & 897 & $*$ & 703 & 530 \\
PSKI & $1.13^{\circ} \mathrm{S}, 100.35^{\circ} \mathrm{E}$ & Indonesia & 703 & 515 & $*$ & $*$ \\
BSAT & $3.08^{\circ} \mathrm{S}, 100.28^{\circ} \mathrm{E}$ & Indonesia & 865 & 679 & 201 & 94 \\
COCO & $12.19^{\circ} \mathrm{S}, 96.85^{\circ} \mathrm{E}$ & Australia & 1725 & 1698 & 986 & 1164 \\
\hline
\end{tabular}

* indicates no data period

to the Malaysian Mapping and Surveying Department (JUPEM) network, PSKI and BSAT are stations of the Sumatran GPS Array (SUGAR) network, while the remaining stations belong to the International GNSS Service (IGS), whereby data are available online.

The GPS TEC is estimated by assuming that the ionosphere is a spherical shell at fixed height of $400 \mathrm{~km}$ above the Earth's surface. The vertically corrected GPS TEC measurements are obtained above $30^{\circ}$ elevation angle using the obliquity correction factor. Generally, GPS TEC can be obtained from both differential group delay (P1-P2) and differential phase advance (L1-L2). The GPS TEC obtained from group delay measurements gives a level of absolute TEC, but with an error worse than $10^{15} \mathrm{~m}^{-2}$ when averaged on a $30 \mathrm{~s}$ interval (Plotkin, 2003). The GPS TEC obtained from phase measurements also gives a high degree of accuracy corresponding to an error of at least $10^{14} \mathrm{~m}^{-2}$ when averaged on a $30 \mathrm{~s}$ interval but with some ambiguity in the initial TEC value (Afraimovich et al., 2001). Therefore, the TEC level is adjusted to the TEC derived from the corresponding code difference for each satellite-receiver pair (Otsuka et al., 2002).

In this work, the absolute TEC is determined by using the geometry-free combination (GFC) of dual-frequency code and phase measurements. The ambiguity term in the TEC is resolved by combining the GFC code with phase measurements for each satellite path using a method derived by Warnant and Pottiaux (2000). For the detailed absolute GPS TEC calculation, readers are referred to Zainol Abidin et al. (2007). The GPS TEC values have been corrected from their satellite biases using the values provided by the AIUB Data Center of Bern University, Switzerland. Meanwhile, the TEC values for the IGS station have been corrected from its receiver biases by using values from the AIUB Data Center of Bern University, while values for the SUGAR and JUPEM stations have been determined by using Bernese version 5.0.

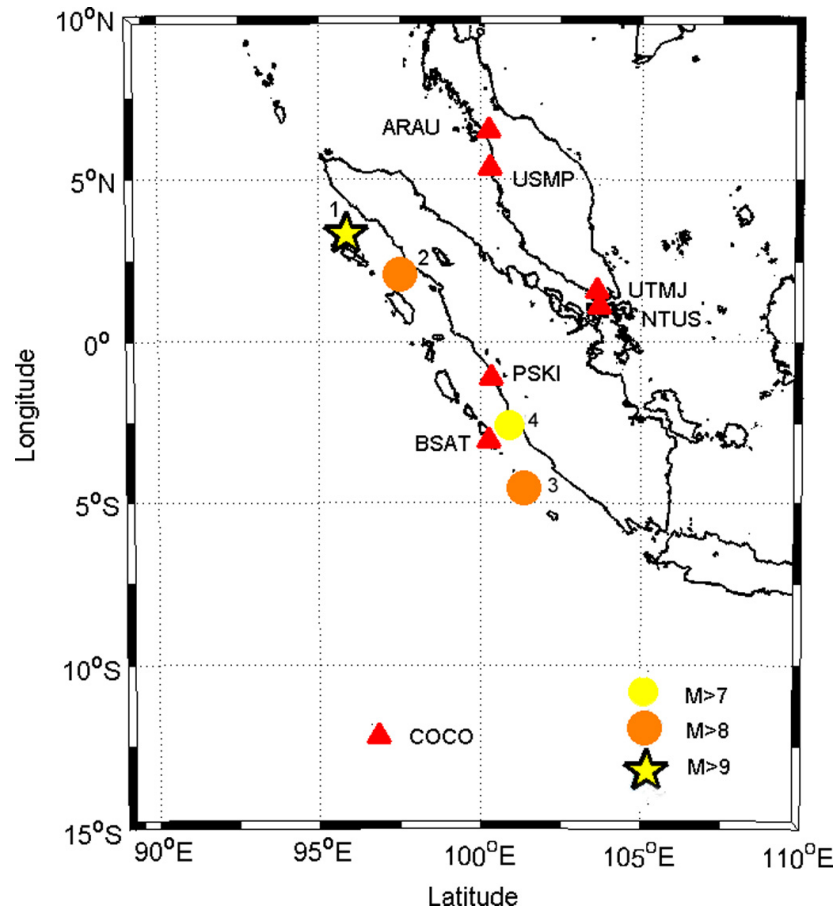

Fig. 1. Geographic locations of the four earthquake epicenters (star and circle) and GPS receiver stations (triangle).

To identify the ionospheric response to earthquakes, the running median of the GPS TEC for the previous 15 days and the associated standard deviation, $\sigma$ are utilized to construct the upper and lower bounds of the inter-quartile range (IQR). These bounds are computed during the earthquake periods to better separate seismic anomalies from natural and seasonal variations (Liu et al., 2004). The upper and lower bounds can be determined using the following formulae:
$\mathrm{IQR}_{\mathrm{UB} / \mathrm{LB}}=\mathrm{TEC}_{\text {median }} \pm 1.34 \sigma$ 
where $\mathrm{TEC}_{\text {median }}$ is the 15-day running median and $\sigma$ is the associated standard deviation.

To quantify the ionospheric disturbances, the percentage of TEC deviation $(\triangle \mathrm{TEC} \%)$ with respect to both the lower and upper bounds has been computed. This index gives information about the positive and negative phases that occur during the earthquake period and can be obtained using the following equations (Dabas et al., 2007):

$$
\begin{aligned}
& \Delta \mathrm{TEC} \%(\text { positive })=\frac{\mathrm{TEC}_{\mathrm{EQ}}-\mathrm{IQR}_{\mathrm{UB}}}{\mathrm{IQR}_{\mathrm{UB}}} \times 100 \\
& \text { If } \left.\mathrm{TEC} \leq \mathrm{IQR}_{\mathrm{UB}} \text {, then } \Delta \mathrm{TEC} \% \text { (positive }\right)=0
\end{aligned}
$$

$\Delta \mathrm{TEC} \%$ (negative) $=\frac{\mathrm{TEC}_{\mathrm{EQ}}-\mathrm{IQR}_{\mathrm{LB}}}{\mathrm{IQR}_{\mathrm{LB}}} \times 100$

If $\mathrm{TEC} \geq \mathrm{IQR}_{\mathrm{LB}}$, then $\triangle \mathrm{TEC} \%$ (negative) $=0$

where $\mathrm{TEC}_{\mathrm{EQ}}$ is the TEC value during the earthquake period. In order to reduce computation time, the $\triangle \mathrm{TEC} \%$ is computed based on a 15-min average TEC. To rule-out the possibility of anomaly detection during high and moderate geomagnetic activity, the $\triangle \mathrm{TEC} \%$ values with $|\mathrm{Dst}|>15 \mathrm{nT}$ and $\mathrm{Kp}>4$ are filtered out from the analysis.

In addition to the ground-based GPS TEC measurements, satellite-based electron density $\left(\mathrm{N}_{e}\right)$ data obtained by a planar Langmuir probe onboard the CHAMP satellite with 15 $\mathrm{s}$ values are also used. CHAllenging Mini-satellite Payload (CHAMP) is a German small satellite mission for geoscientific and atmospheric research and applications, managed by the GFZ German Research Centre for Geosciences (http://isdc.gfz-potsdam.de). CHAMP was launched on 15 July 2000 into an almost circular and near polar orbit with an inclination of $87^{\circ}$ and $450 \mathrm{~km}$ in altitude. The satellite moves in the meridional direction almost at the height of the ionospheric electron concentration maximum. To analyze the pre-earthquake modification of the equatorial ionosphere, the electron density $\left(\mathrm{N}_{e}\right)$ measurements obtained from the magnetic and electric field data of level 2 (CH-ME-2-PLP) are examined. The CH-ME-2-PLP data, which are available in dat format are preprocessed, edited, calibrated, supplemented with necessary spacecraft housekeeping data and arranged in daily files. The CHAMP $\mathrm{N}_{e}$ measurements have been successfully used by Zakharenkova et al. (2008) to confirm the presence of the EA modification observed in the GIM TEC during a few days before the 26 September 2005 Peru earthquake. In this analysis, the $\mathrm{N}_{e}$ variations along the longitude range of $75-135^{\circ} \mathrm{E}$ during a few days before the earthquakes are analyzed.

\section{Results and discussion}

The ionospheric perturbations prior to the 26 December 2004, 28 March 2005 and 12 September 2007 Sumatra earthquake events are investigated. In this work, the diurnal TEC variations and the percentage of TEC deviation are analyzed for the period of several days before, during and a day after the event. In order to examine whether the earthquakes occurred during low or strong geomagnetic conditions, the diurnal TEC variations are analyzed alongside the geomagnetic data obtained from the WDC (http://swdcwww.kugi.kyoto-u.ac.jp)

The electron density $\left(\mathrm{N}_{e}\right)$ obtained from CHAMP satellite measurements over the earthquake epicenters are also examined. The 4 events are discussed in the following sections:

\subsection{Analysis of the ionospheric variations before the 26 December 2004 earthquake}

The Sumatra-Andaman earthquake of 26 December 2004 is the fourth largest earthquake in the world since 1900 and is the largest since the 1964 Prince William Sound, Alaskan earthquake. The earthquake occurred off the west coast of Northern Sumatra near Banda Aceh, Indonesia at 00:58 UT with a magnitude of M9.3 and depth of $30 \mathrm{~km}$ as shown in Table 1. Figure 2 presents the geomagnetic indices Dst, AE, $\mathrm{Kp}$ and Ap, and the TEC variations and the associated upper and lower bounds for the observation period between 16 and 27 December 2004 observed at 6 GPS stations. The vertical dashed line in the figure marks the time of the earthquake. The horizontal dashed lines in Fig. 2a-b show the threshold values of the Dst and Kp indices, which are $15 \mathrm{nT}$ and 4, respectively. The crosses in Fig. 2c-h show detections of TEC values, which exceed the upper and lower bounds using the method discussed in Sect. 2. In these figures, detections were seen between the period of 10 days and a few hours before the event at all the 6 stations. The detections were also observed a day after the event but they are due to the aftershocks of the earthquake. However, as indicated by the Dst, AE, $\mathrm{K}$ amd Ap indices in Fig. 2a-b, the geomagnetic conditions during the days of 16,21, 22 and 25 December were disturbed, while the geomagnetic levels on 19 and 20 December were characterized as quiet. Therefore, only TEC anomalies observed on 19 and 20 December are considered as possible pre-earthquake ionospheric anomalies, hence they are highlighted by the $\mathrm{P}$ character and the ones seen on disturbed days are highlighted by the $\mathrm{D}$ character.

Figure 3 shows the percentage of TEC deviation for the same observation period presented in Fig. 2. In this figure, the positive and negative values of the filtered $\triangle \mathrm{TEC} \%$ show the variation with respect to the upper and lower bound, respectively. Referring to the days highlighted in Fig. 3, significant increases in $\triangle \mathrm{TEC} \%$ of about $17-87 \%$ were observed simultaneously from 18:00-23:00 UT on 19 and 20 December 2004 at ARAU, USMP, UTMJ, NTUS and PSKI stations but were not observed at COCO station. The precursory effects of the great Sumatra-Andaman earthquake have already been reported by Dabas et al. (2007) and Saroso et al. (2008) using ground-based measurements obtained from a single 


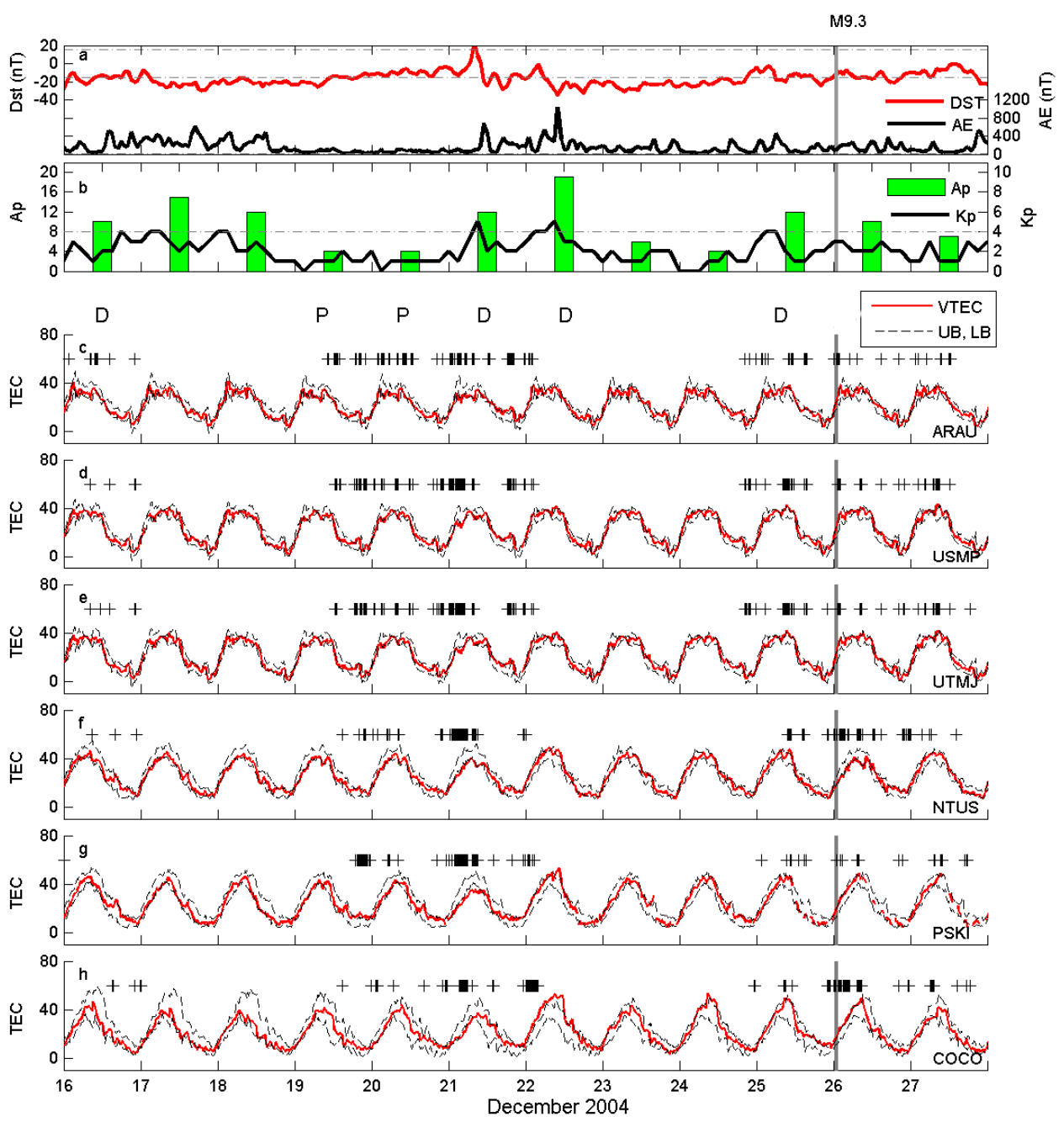

Fig. 2. The geomagnetic indices (a) Dst and AE, (b) Ap and Kp, and the (c)-(h) TEC variations and the associated upper and lower bounds between 16 and 27 December 2004 at 6 GPS stations.

station at New Delhi and Indonesia, respectively. However, it has again been examined regarding this result for the comparison between ground and satellite-based ionospheric measurements.

To investigate the temporal and spatial variations of the TEC anomalies before the event, measurements from individual satellites are examined. This analysis gives better insight on the effect and possible locations of the ionospheric anomalies. As shown in Figs. 2-3, TEC anomalies were detected on 19 and 20 December 2004 at 6 GPS stations. We zoom in on the TEC variations between 17:00 and 22:00 UT on 19 and 20 December for satellite 15 and the upper bound of 19 December at 6 GPS stations as shown in Fig. 4. The right panel of the figure illustrates the epicenter and the satellite trajectories above the respective GPS stations on 19 December. As shown in Fig. 4, the TEC measurements on 19 and 20 December show variability from one station to another. During both days, TEC increases of about 2-5 TECU with respect to the upper bound were generally observed from 18:00-22:00 UT almost simultaneously at ARAU, USMP and UTMJ stations. The TEC at both NTUS and PSKI stations on 19 December only started to increase from 19:00-22:00 UT, while the TEC on the following day did not show any significant variation. Meanwhile, no increase in TEC was observed on both days at COCO station. It is worth mentioning that the TEC variations which fall below the upper bound level are not considered as positive anomalies, as formulated in Eq. (2). It was observed that the TEC increases detected by satellite 15 correlate well with the increases found in the $\triangle \mathrm{TEC} \%$ shown in Fig. 3. These positive anomalies were observed within the boundary of the earthquake preparation zone at distances ranging from 500 $1700 \mathrm{~km}$ from the epicenter. In order to confirm the GPS TEC anomalies on 19 and 20 December, the CHAMP electron density measurements during these days were obtained from GFZ (http://isdc.gfz-potsdam.de). Unfortunately, the 


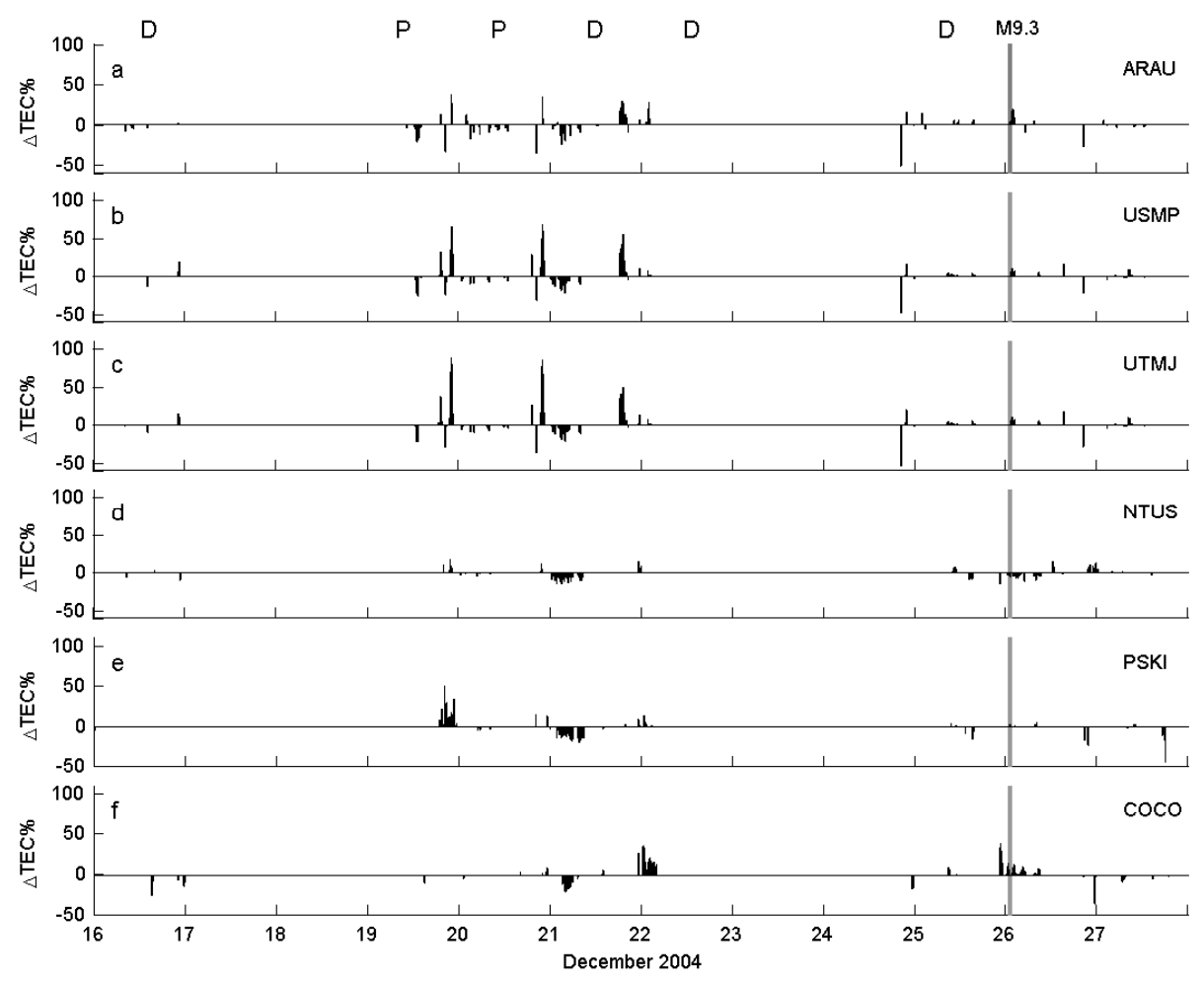

Fig. 3. The percentage of TEC deviation between 19 and 27 December 2004 at 6 GPS stations. The positive and negative values show the filtered $\triangle \mathrm{TEC} \%$ variations with respect to their upper and lower bound, respectively.

$\mathrm{N}_{e}$ measurements during the observation time of the TEC anomalies could not be examined due to data inavailability.

As shown earlier in Fig. 3, significant increases and decreases were found during 5-6 days (LT) before the $26 \mathrm{De}-$ cember 2004 earthquake, which occur during very quiet geomagnetic conditions. However, Kazimirovski (2002) stated that the TEC also generates significant day-to-day variations during magnetically quiet periods due to the thermospheric dynamics caused by different types of atmospheric disturbances from the lower atmosphere. Earlier observations have confirmed that the day-to-day TEC variability caused by thermospheric dynamics in the equatorial latitudes does not usually exceed 20\% (Forbes et al., 2000; Rishbeth and Mendillo, 2001; Bilitza et al., 2004). Our result shows that the maximum values of the pre-earthquake daytime positive anomalies exceeded 20\%. Dabas et al. (2007) also found such anomalies in the foF 2 measurements about 6 days before the same earthquake but they appear to be much weaker than the ones observed in this result. Afraimovich et al. (2004); Heki et al. (2006) and Otsuka et al. (2006) observed strong coseismic and post-seismic ionospheric disturbances from $10 \mathrm{~min}$ to several hours after this event but they are not apparently seen in our results. Since the GPS TEC measurements determined in this analysis were obtained from all satellites, above the elevation mask angle of $30^{\circ}$ and averaged over a $15-\min$ period, the TEC oscillation due the major event using this method cannot be clearly observed.

\subsection{Analysis of the ionospheric variations before the 28 March 2005 earthquake}

The 28 March 2005 earthquake occurred with a magnitude of 8.6 at 16:05 UT in North Sumatra. The same analysis presented in Figs. 2 and 3 was repeated for the 28 March 2005 earthquake period, whereby the geomagnetic indices and diurnal TEC as well as $\triangle$ TEC $\%$ variations between 18 and 29 March 2005 at 4 GPS stations are analyzed as shown in Figs. 5 and 6, respectively. As shown in Fig. 5, sudden decreases in TEC were observed during 14:00-16:00 UT, particularly on 22, 23 and 28 March. To check for F-region plasma depletion, the half-orbit of level 2 electron density $\left(\mathrm{N}_{e}\right)$ and temperature $\left(\mathrm{T}_{e}\right)$ data measured by the Langmuir Probe instrument (ISL) onboard the DEMETER satellite (http://demeter.cnrs-orleans.fr) are examined throughout the observation period prior to the event. Plasma depletions were found during the hours of 14:00-16:00 UT near the magnetic equator by satellite orbits 03826_1, 03827_1, 03828_1 (22 March), 03840_1, 03841_1, 03842_1 (23 March) and $03915 \_1$ ( $\left.28 \mathrm{March}\right)$ at longitudes $85-135^{\circ}$ E. Figure 5 


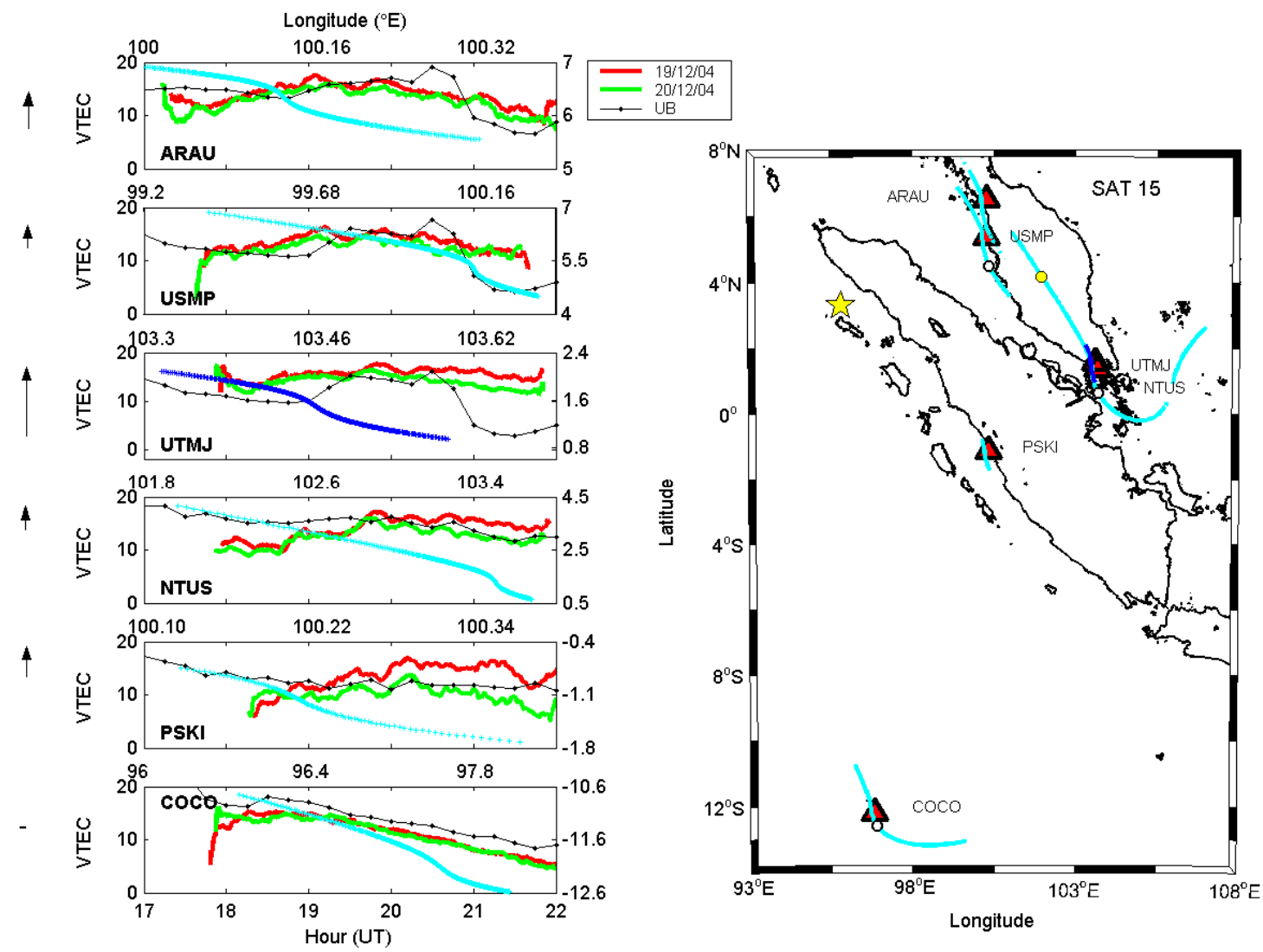

Fig. 4. Temporal and spatial TEC variations as well as the associated upper bound at 6 GPS stations for satellite 15 observed during 17:0022:00 UT on 19 and 20 December 2004. The right panel of the figure shows the satellite trajectories on 19 December. The solid and open circles denote time marks for the start and end of the observation period, respectively.

shows the some of these plasma depletions observed by orbits 03827_1 on 22 March, 03841_1 on 23 March and 03915_1 on 28 March. In the figure, the vertical blue line shows the latitude of the eartquake epicenter. As the GPS stations considered in our study are located near the magnetic equator, the sudden decrease in the local TEC are most likely the manisfestation of equatorial plasma depletion, which normally occurs at night even during geomagnetically quiet periods (Sahai et al., 1999). Therefore, detections of TEC anomalies and $\triangle \mathrm{TEC} \%$ values for temporal intervals of 14:00-16:00 UT on the affected days are removed from the analysis. In Fig. 6, detections were found mostly from 22-27 March but only the days of 22-24 March are most likely related to the earthquake event, as the period coincides with geomagnetically quiet days. Meanwhile, the anomalies detected on 25-27 March cannot be convincingly regarded as earthquake precursors since they occurred on geomagnetically disturbed days.

As shown in Fig. 7, both positive and negative anomalies were clearly observed in the $\triangle \mathrm{TEC} \%$ at all 4 stations during the range of 4-6 days before the event. During 22 March, it was observed that the sign of the $\triangle \mathrm{TEC} \%$ observed during 03:00-12:00 UT varies from one station to another. Only $\triangle \mathrm{TEC} \%$ decreases were seen at ARAU station, whereas both increases and decreases were detected at PSKI and BSAT. The $\triangle \mathrm{TEC} \%$ at COCO station on the other hand, detected only increases. The anomaly during this day is most intense at COCO station, which is located at the southern crest of the EA with a maximum increase of about $67 \%$. Such an enhancement was also reported by Dabas et al. (2007) on 22 March at the ionosonde station located in the northern crest of the EA. During 23 and 24 March, decreases of about 20\% were found at ARAU, PSKI and BSAT stations, while no data is available at COCO during these days.

To confirm the GPS TEC anomalies, the electron density measurements obtained from CHAMP satellite were examined. Prior to the 28 March 2005 earthquake, CHAMP was flying along the longitude sector of about $75-125^{\circ} \mathrm{E}$ during the local afternoon hours $(\mathrm{LT}=\mathrm{UT}+8)$. Figure 8 a presents the $\mathrm{N}_{e}$ variations during 06:00-08:00 UT (14-16 LT) on 22, 23 and 24 March 2005 and the median of 11-20 March 2005 near the longitude sector of the epicenter $\left(\sim 100^{\circ} \mathrm{E}\right)$. In this 


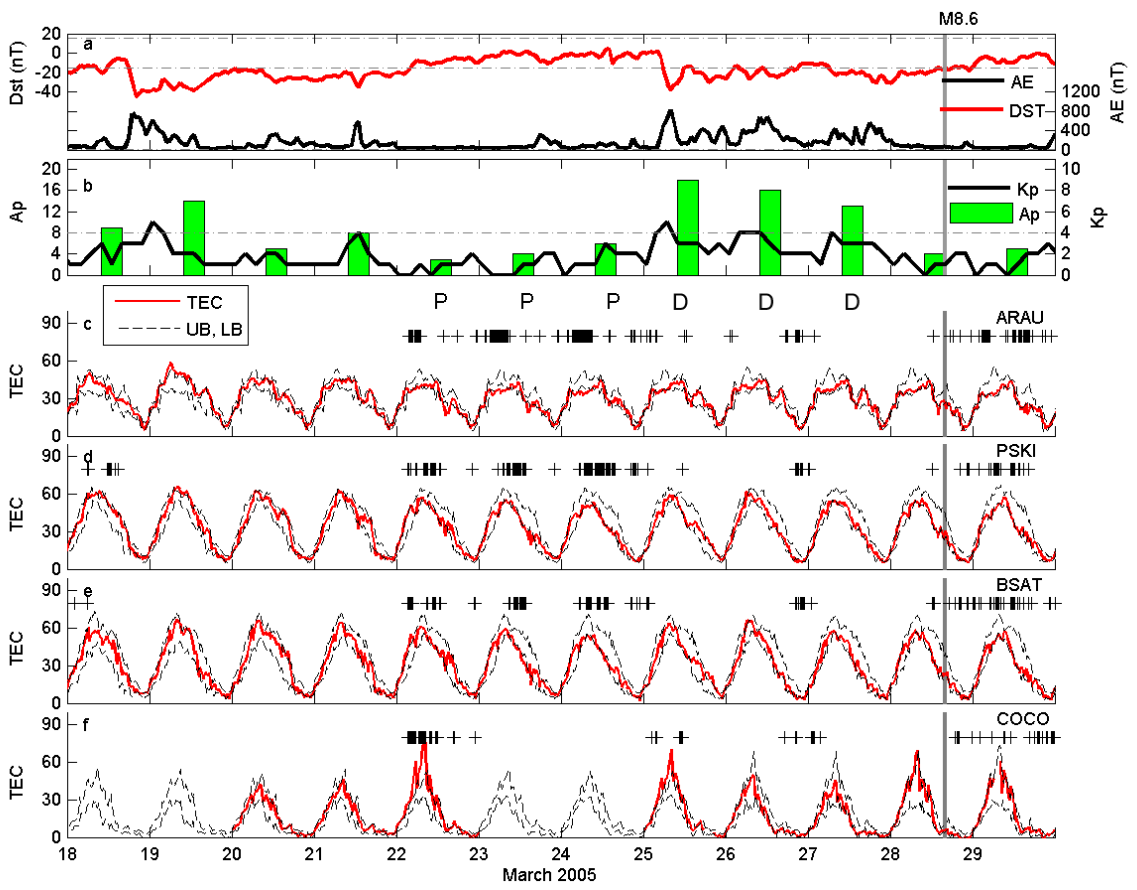

Fig. 5. The geomagnetic indices (a) Dst and AE, (b) Ap and Kp, and the (c)-(f) TEC variations and the associated upper and lower bounds between 18 and 29 March 2005 at 4 GPS stations.
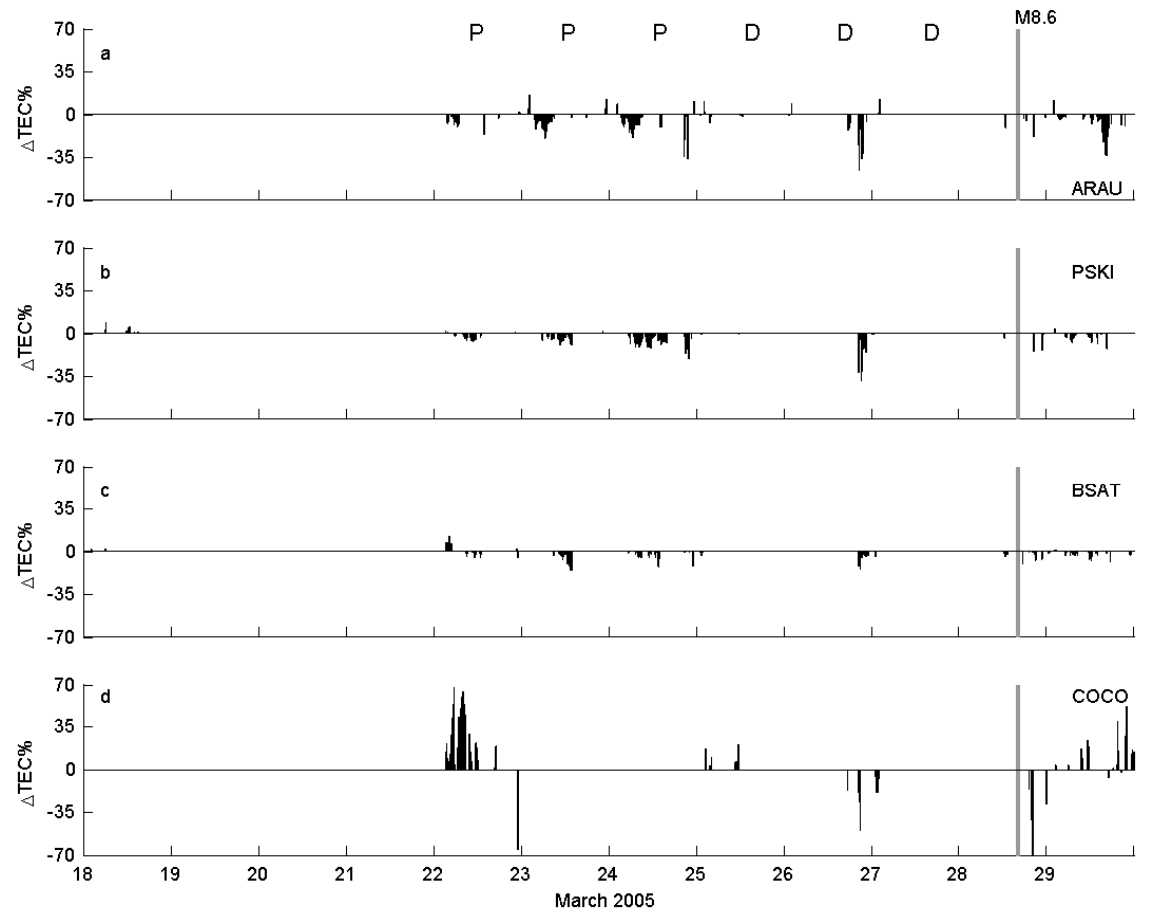

Fig. 6. The percentage of TEC deviation between 21 and 29 March 2005 at 4 GPS stations. 
a
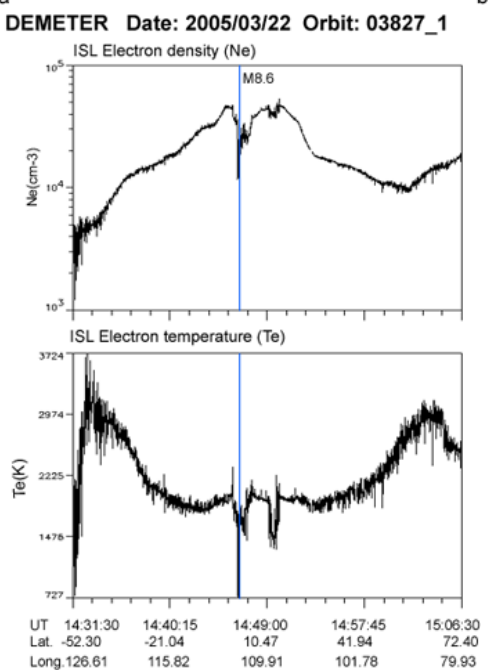

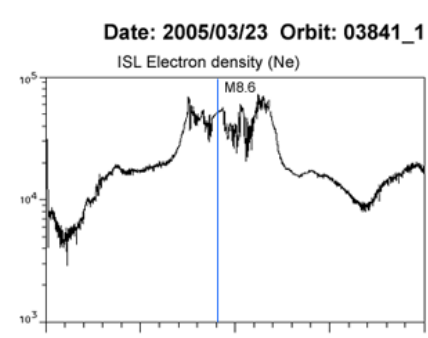

ISL Electron temperature (Te)

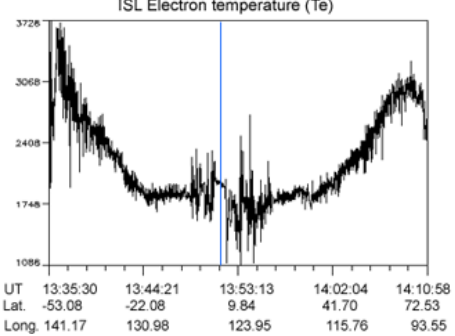

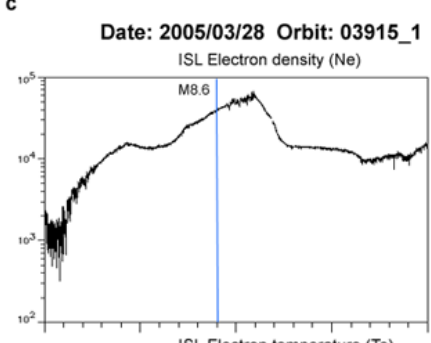

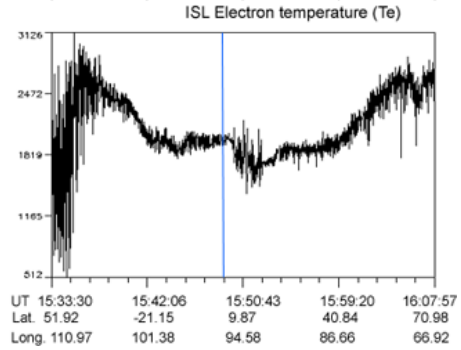

Fig. 7. The plasma depletions observed in the DEMETER electron density and temperature measurements near the epicenter by satellite orbits (a) 03827_1 on 22 March 2005, (b) 03841_1 on 23 March 2005 and (c) 03915_1 on 28 March 2005. The vertical line shows the latitude of the earthquake epicenter.
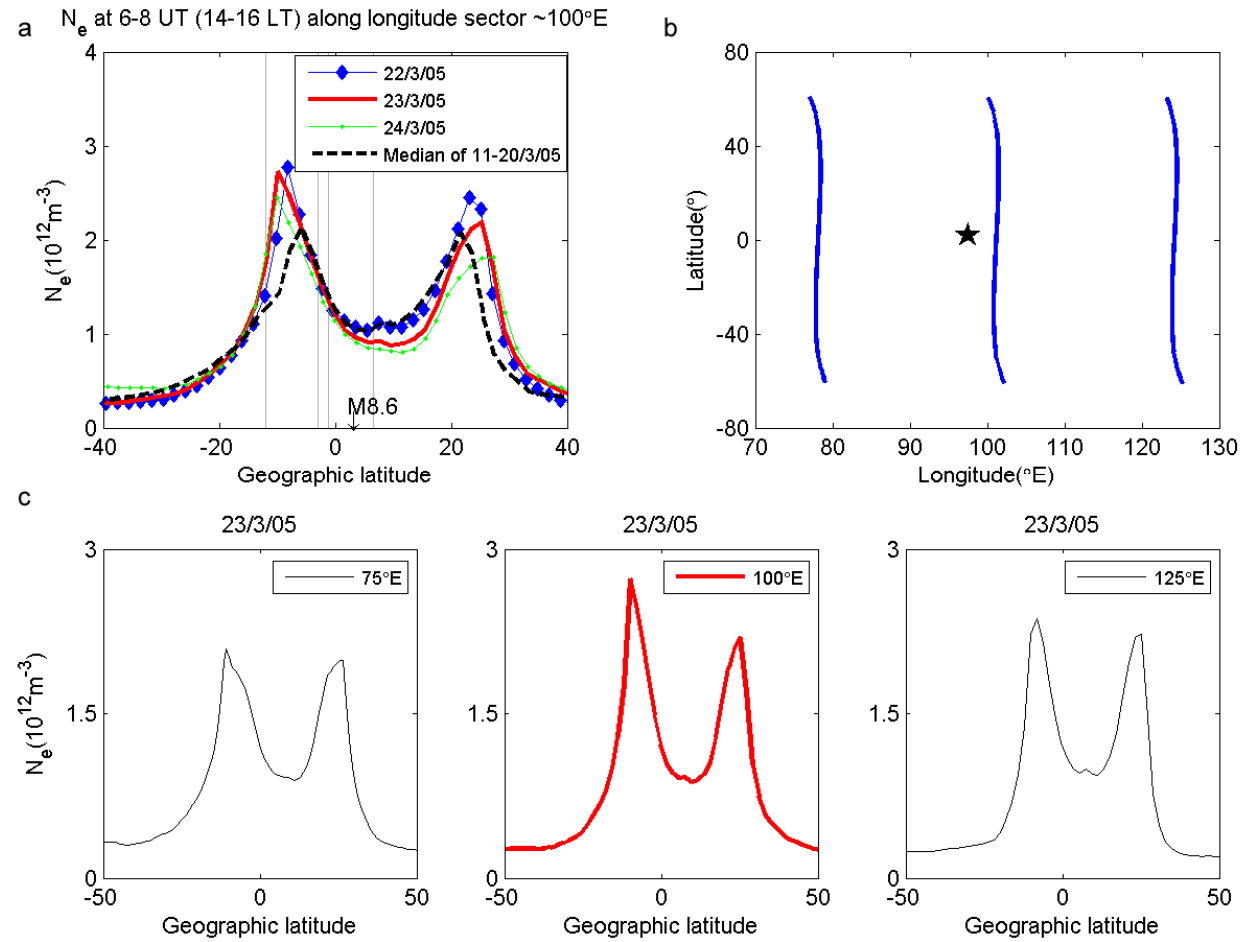

Fig. 8. (a) The CHAMP $\mathrm{N}_{e}$ variations observed from 06:00-08:00 UT on 22, 23 and 24 March 2005 and the median for 11-20 March along the longitude of about $100^{\circ} \mathrm{E}$. The vertical lines mark the latitude positions of the GPS stations. (b) The geographical projection of the satellite passes and (c) $\mathrm{N}_{e}$ measurements along the longitudes of $75^{\circ} \mathrm{E}, 100^{\circ} \mathrm{E}$ and $125^{\circ} \mathrm{E}$ on $23 \mathrm{March}$. 
figure, the vertical lines mark the latitude positions of the COCO, BSAT, PSKI and ARAU stations, arranged in the order of ascending latitude (from left to right). Figures $8 \mathrm{~b}-\mathrm{c}$ show the geographical projections of three satellite passes along the longitudes of 75,100 and $125^{\circ} \mathrm{E}$ on 23 March and their $\mathrm{N}_{e}$ measurements, respectively. The temporal shift of each satellite is about $1.5 \mathrm{~h}$. As shown by the median value in Fig. 8a, the usual EA in the afternoon appears in the form of a double-crest structure with a trough over the magnetic equator. However, the EA modification in the form of crest amplification and trough deepening in the near-epicentral region with respect to the median value was observed between 4 and 6 days prior to the event. During these days, the electron concentration at the crest increases and trough decreases by about 40 and $20 \%$, respectively relative to the median value. This phenomenon was also reported a few hours before the 20 March 1979 earthquake, whereby Pulinets and Lagen'ka (2002) observed significant EA trough deepening and the crest amplification in the afternoon using the topside foF2 measurements onboard the Intercosmos-19 satellite. In Fig. 8c, it is evident that the EA amplification that took place particularly in the southern crest was clearly seen near the epicenter region but was not observed along the longitude of $75^{\circ} \mathrm{E}$ on $23 \mathrm{March}$. The crest amplification also occurred at longitude $125^{\circ} \mathrm{E}$ but its amplitude is not as pronounced as the one near the epicenter. Hence, we believe that the EA amplification that occurred during 4-6 days before the earthquake has a local character and might be due to the earthquake preparation.

\subsection{Analysis of the ionospheric variations before the 12 September 2007 earthquakes}

Two large earthquakes occurred in South Sumatra on 12 September 2007 with magnitudes of M8.5 and M7.9 at 11:10 UT and 23:49 UT, respectively. The result of TEC and $\triangle \mathrm{TEC} \%$ variations at NTUS, BSAT and COCO stations for the period between 6 and 13 September 2007 is presented in Figs. 9 and 10, respectively. As shown in Fig. 9, pronounced detections were found from 8 to 12 September, but the detection on 8 September is probably the ionospheric response due to the time delay effects of the sudden storm commencement on 6 September. Based on this observation, only the TEC anomalies from 9-12 September are considered as possible earthquake-related anomalies, as they were detected during very quiet geomagnetic conditions. In Fig. 10, $\triangle$ TEC\% increases and decreases were observed almost simultaneously at all 3 GPs stations between 3 days and a few hours before the events. The $\triangle \mathrm{TEC} \%$ increases of about $16-55 \%$ were observed during 13:00-20:00 UT on 9, 11 and 12 September, while the decreases of about $17-40 \%$ were seen during 05:00-09:00 UT on 9, 10 and 11 September. It was observed that the $\triangle \mathrm{TEC} \%$ variations were more prominent at BSAT and COCO stations than that at NTUS, although NTUS is located about $300-600 \mathrm{~km}$ nearer to the earthquake epicen- ters than COCO. During a few hours before the second event (M7.9), increases in $\triangle$ TEC $\%$ of about $20 \%$ were observed at all 3 stations but the most intense anomaly was seen at BSAT station, which is closest to the epicenter $(94 \mathrm{~km})$.

Fig. 11a presents the $\mathrm{N}_{e}$ variations during 07:00-09:00 UT (15-17 LT) between 9 and 12 September 2007 and the median of 1-5 September near the longitude sector of the epicenter $\left(\sim 110^{\circ} \mathrm{E}\right)$. The vertical lines in the figure mark the latitude positions of COCO, BSAT and NTUS stations. The geographical projections of three satellite passes along the longitudes of 85,110 and $135^{\circ} \mathrm{E}$ on 9 September and their $\mathrm{N}_{e}$ measurements, respectively are shown in Figs. 11b-c. As shown in Fig. 11a, an EA modification in terms of crest disappearance and crest displacement over the magnetic equator was observed on 9 September 2007. No EA modification was seen on 10,11 and 12 September but the $\mathrm{N}_{e}$ measurements mostly show decreases at the latitude positions of NTUS, BSAT and COCO stations. Similar to the observation of $\triangle \mathrm{TEC} \%$ variation in Fig. 9, it is also shown that larger $\mathrm{N}_{e}$ variations were observed at the positions of BSAT and COCO stations than the one observed at the position of NTUS station. In Fig. 11c, the comparison between the $\mathrm{N}_{e}$ measurements at longitudes 85,110 and $135^{\circ} \mathrm{E}$ shows that the daytime EA modification on 9 September did not take place at $85^{\circ} \mathrm{E}$ but was observed near the two earthquake epicenters. However, the fact that the same modification was found along the longitudes ranging from $135-170^{\circ} \mathrm{E}$ and even 2 weeks after the event (not shown in the result), suggests seasonal effects on the EA behaviour and no link with the 12 September 2007 earthquakes.

Table 3 summarizes the results of the ionospheric anomalies in the GPS TEC and $\mathrm{N}_{e}$ measurements detected before the 4 large earthquakes. In this table, the day, the local time of the stations $(\mathrm{LT}=\mathrm{UT}+8)$, the average of the maximum $\triangle \mathrm{TEC} \%\left(\triangle \mathrm{TEC} \%_{\max }\right)$ and $\Delta \mathrm{N}_{e} \%$ and the position of the detected anomaly in the EA region are shown. The position of each detected anomaly is indicated either in the trough or crest region of the EA. The average $\triangle \mathrm{TEC} \%_{\max }$ at the trough is determined by averaging the maximum $\triangle \mathrm{TEC} \%$ values at all the stations considered, while the value at the crest is obtained by taking the maximum $\triangle \mathrm{TEC} \%$ at COCO station. Meanwhile, the average $\Delta \mathrm{N}_{e} \%$ is obtained by averaging the values at the latitude positions of the considered GPS stations in the trough and crest regions.

The table shows that both positive and negative ionospheric anomalies were detected in the GPS TEC between 6 days and a few hours before the 4 large earthquakes in Sumatra. The positive TEC anomalies were mostly seen during post-midnight to early morning hours (1-7 LT), while the negative TEC anomalies were mostly observed during the afternoon hours (12-17 LT). These anomalies were also confirmed by the CHAMP electron density measurements. It is shown that most of the significant TEC and $\mathrm{N}_{e}$ variations have similar signs. As shown in Table 3, the maximum variation of these anomalies mostly occurs in the daytime 
Table 3. The ionospheric anomalies detected before the 4 large earthquake events. The day is relative to the earthquake day.

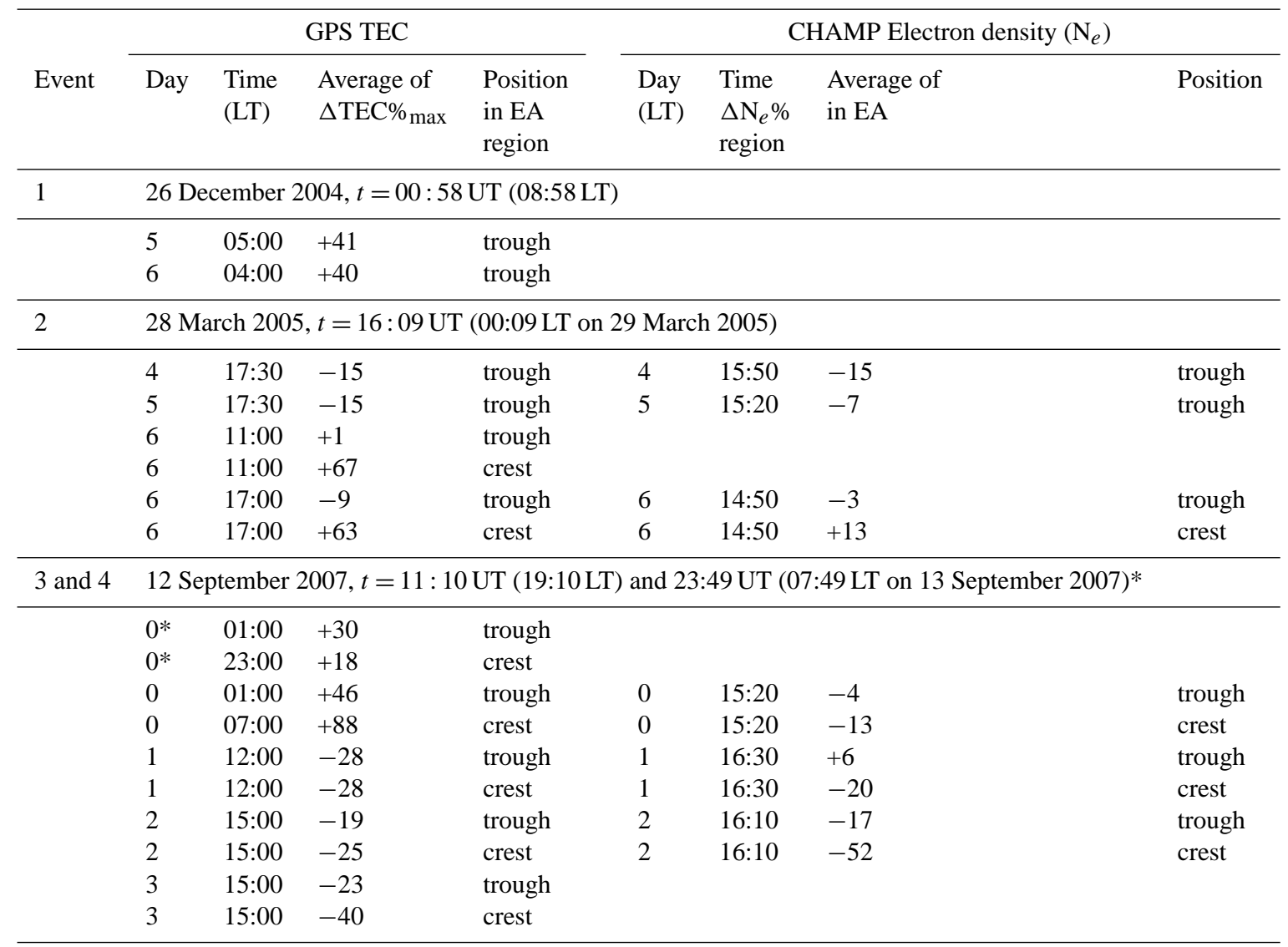

*Precursor of the M7.9 earthquake on 12 September 2007 (23:49 UT).

hours between 4 and 17 LT prior to the events. Hobara and Parrot (2005) also found ionospheric anomalies in the daily $\Delta$ foF2 variation between 4 and 17LT during 4-9 days before the 1968 Hachinohe earthquake in Japan. Our results show that the daytime TEC anomalies are in close approximation with their observation as well as with those reported by Dabas et al. (2007) and Sharma et al. (2008).

As shown in the table, the observations prior to the earthquake events $2-4$ show that the magnitude of the local TEC anomalies does not only depend on their distances to the epicenter but also by their latitude positions in the EA. In our result, the magnitude of the anomalies detected during the daytime is larger at the station located in the crest region (COCO) as compared to those in the trough region. Previous observation made by Sharma et al. (2008) before the 1967 Koyna earthquake showed that the ionospheric anomalies detected in the EA trough region during nighttime were of higher magnitudes than those in the northern crest region although they are located further from the epicenter. Their observation were attributed to the migration of ionospheric anomalies to the direction of the equatorward meriodional winds and the $\mathrm{E} \times \mathrm{B}$ drift during the nighttime. In contrast to their observation, the TEC anomalies in this result were mostly observed in the daytime, during which the direction of meridional winds is toward the crests. It is possible that the anomalies generated within the earthquake preparation zone follow the same direction and appear to be more pronounced in the near crest region as shown in Figs. 6d and 10c. The upward $\mathrm{E} \times \mathrm{B}$ drift due to the eastward electric fields in the afternoon can also play a significant role for directing these anomalies towards the crest from the equator.

As shown earlier in Fig. 8, the daytime EA modification in terms of crest amplification occurred during a few days before the 28 March 2005 earthquake. It was also observed that the amplitude of the crest amplification decays far away from the epicenter. Pulinets and Boyarchuk (2004) stated that the eastward electric field is responsible for the EA development in the afternoon. If the earthquake preparation area lies between the crests of the EA close to the magnetic equator, the anomalous upward electric field from the epicenter will interact with the eastward electric field, which will result in EA shape distortions. Sorokin and Chmyrev (1999) and Pulinets and Boyarchuk (2004) explained the upward seismogenic electric field in relation to 

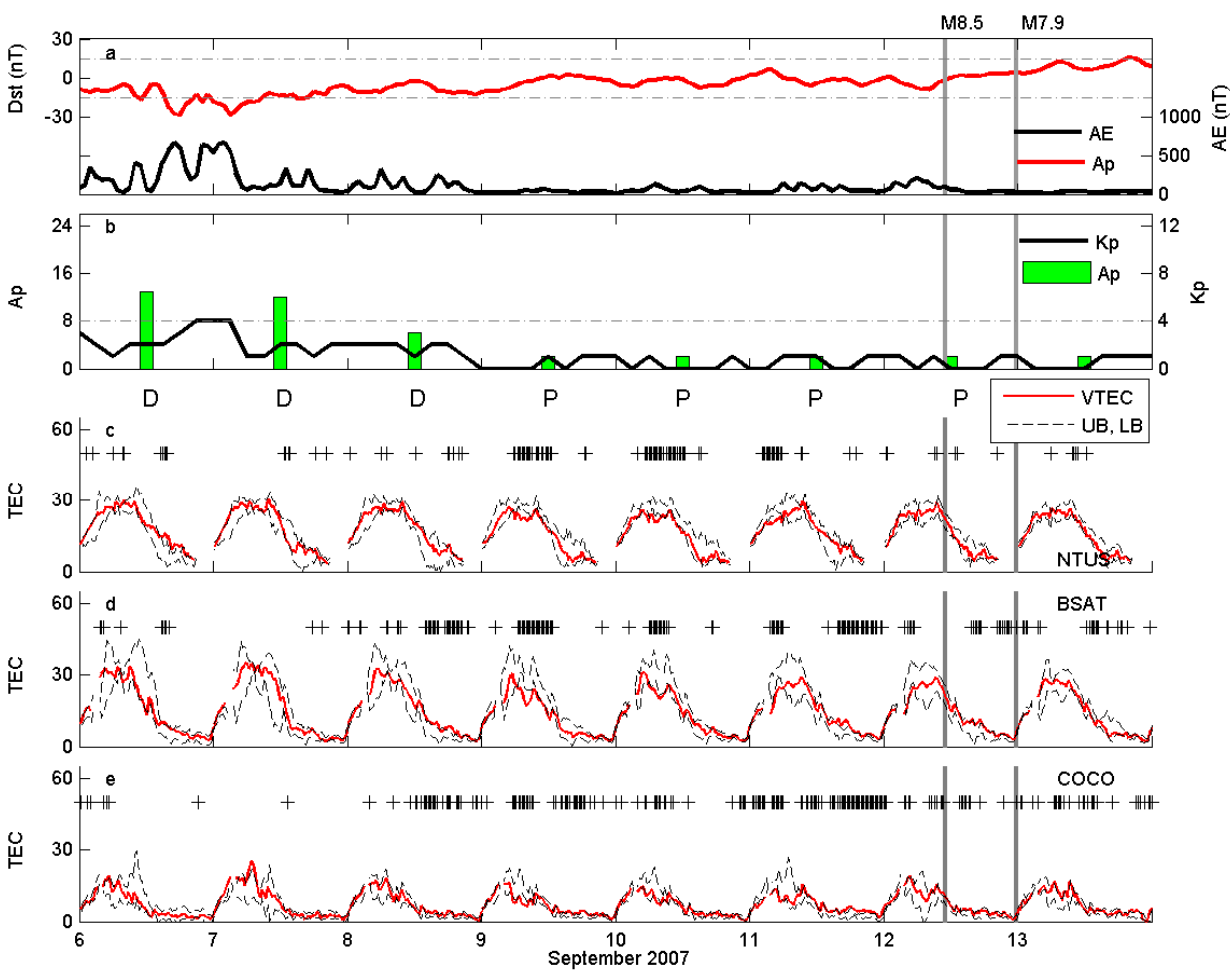

Fig. 9. The geomagnetic indices (a) Dst and AE, (b) Ap and Kp, and the (c)-(e) TEC variations and the associated upper and lower bounds between 6 and 13 September 2007 at 3 GPS stations.
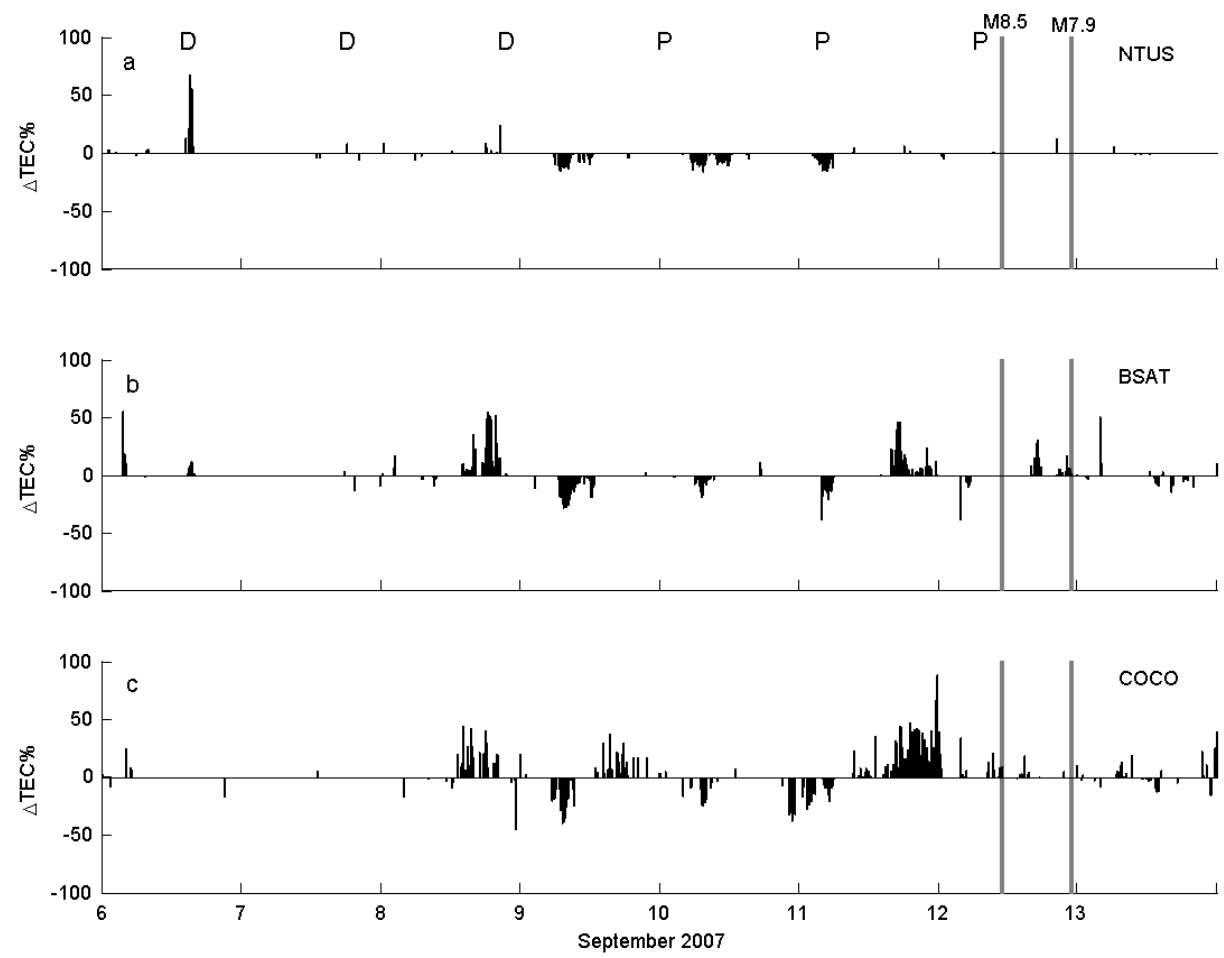

Fig. 10. The percentage of TEC deviation between 6 and 13 September 2007 at 3 GPS stations. 

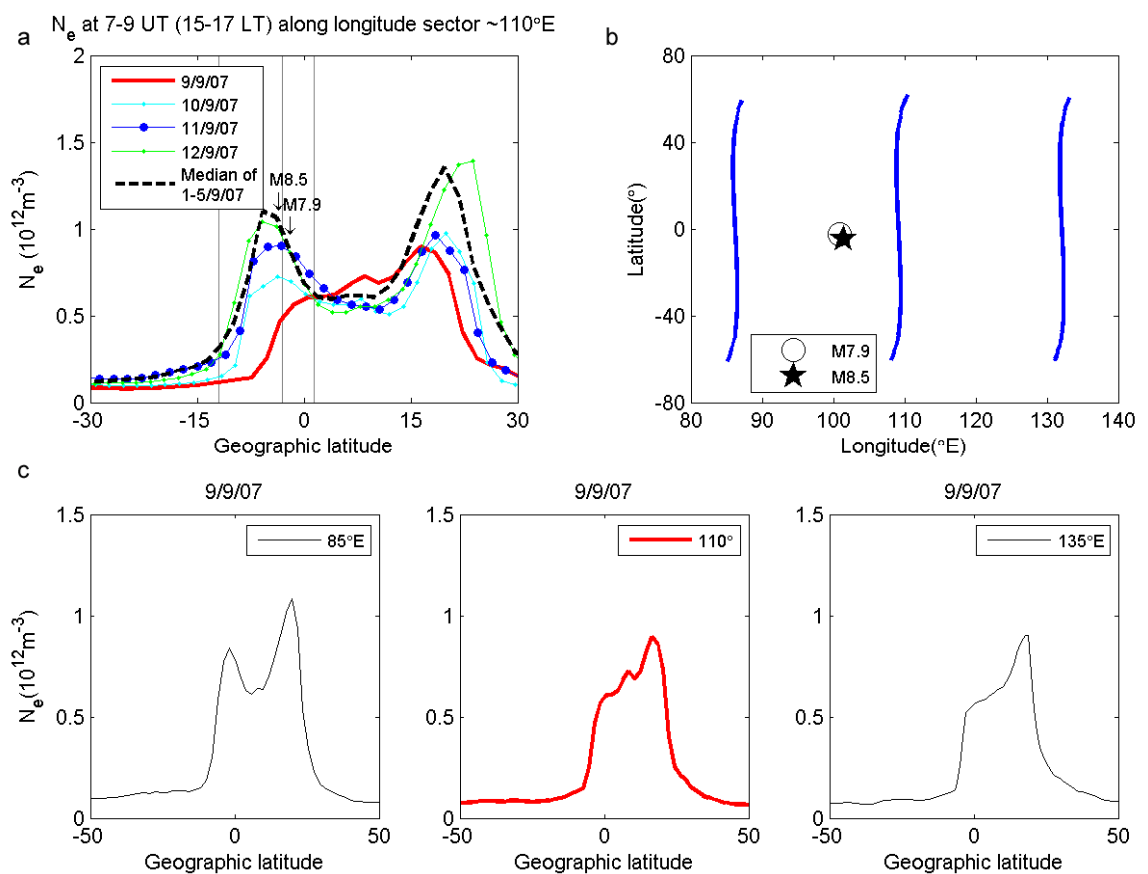

Fig. 11. The CHAMP $\mathrm{N}_{e}$ variations observed from 07:00-09:00 UT between 9 and 12 September 2007 and the median of 1-5 September. The latitude positions of COCO, BSAT and NTUS stations are also shown. (b) Satellite passes on 9 September and (c) $\mathrm{N}_{e}$ measurements along the longitudes of $85^{\circ} \mathrm{E}, 110^{\circ} \mathrm{E}$ and $135^{\circ} \mathrm{E}$.

the vertical turbulent transportation of injected aerosols and radioactive particles. The increase in the atmospheric radioactivity level during the earthquake preparation leads to increases in ionization and electric conductivity at the nearground atmosphere. The joint action of these processes subsequently leads to the intensification of the electric field in the atmosphere and ionosphere. The anomalous vertical electric field has been reported to have peak-to-peak variations of up to $1.5 \mathrm{kV} / \mathrm{m}$ during a few hours before earthquakes in Russia and China (Vershinin, 1999; Hao et al., 2000). Only the electric field, which is perpendicular to the geomagnetic field lines, penetrates into the ionosphere causing electron density irregularities (Kim and Hegai, 1997).

Pulinets and Lagen'ka (2002) and Ruzhin et al. (1998) reported trough deepening and crest amplification using upper ionospheric data from INTERCOSMOS-19 and ALOUETTE satellites, respectively, before some strong equatorial earthquakes. Ruzhin et al. (1998) stated that the generation of anomalous eastward electric field during the earthquake preparation process together with the Earth's magnetic field at the ionospheric level may cause the intensification of the fountain effect. Namgaladze et al. (2007) proposed the vertical drift of the F2-region ionospheric plasma under the influence of zonal electric fields of seismogenic origin. To check this hypothesis, model calculations were carried out using the Upper Atmosphere Model (UAM), which is a global numerical model of the Earth's upper atmosphere. In this model, the ionospheric response to the action of zonal electric fields of seismogenic sources at low latitude was investigated by switching on the electric field sources in the UAM electric potential equation. It was shown that the action of the nearequatorial source intensifies the EA in the near-epicentral area of the ionosphere by deepening the minimum of foF2 over the magnetic equator and displacing the crests from the equator to the middle latitudes. Based on these observations and hypotheses, our results supported the fact that the anomalous upward electric field generated near the epicenter region interacts with the eastward electric field, hence inducing the ionospheric anomalies in the near epicenter region and equatorial anomaly shape distortions.

\section{Conclusions}

The paper investigates the ionospheric perturbations before $4 M \geq 7.0$ earthquake events in the Sumatran region using GPS stations surrounding the epicenters and CHAMP satellite data. In this study, we have shown the efficiency of GPS data to observe anomalies in the TEC variations and also the CHAMP Langmuir probe to detect anomalies in the electron density parameter near large earthquake epicenters a few days before their occurrences. Our results show that positive as well as negative anomalies were observed mostly during the daytime from a few hours to 6 days before these 
events. Prior to the earthquakes, the GPS TEC and electron density measurements show similar tendencies but both show variability in the trough and crest regions. This variability is probably due to the direction of meriodional winds and eastward electric fields towards the crests during the daytime as well as the EA modifications that occurred a few days before the earthquakes. The EA modification appears in the form of crest amplification during the daytime. We conclude that the EA amplification is caused by the vertical drift of the F2-region ionospheric plasma under the influence of zonal electric fields of seismogenic origin. The results of the GPS TEC and electron density anomalies were mostly in close agreement, suggesting that the anomalous upward seismogenic electric field interacts with the eastward electric field and induces the ionospheric anomalies in the near epicenter region as well as the equatorial anomaly shape distortion. However, a null hypothesis test should be conducted in the future to test if significant TEC variations also occur during non-earthquake periods. With respect to this problem, the long-term statistical analysis of temporal and spatial correlation between significant TEC variations and earthquake occurrences will be performed in a separate article.

Acknowledgements. The authors of this paper would like to thank the JUPEM network and SOPAC data archive for supplying free GPS data. The authors would also like to acknowledge GFZ for the provision of CHAMP electron density data.

Edited by: M. E. Contadakis

Reviewed by: three anonymous referees

\section{References}

Afraimovich, E. L., Perevalova, N. P., Plotnikov, A. V., and Uralov, A. M.: The Shock-acoustic waves generated by earthquakes, Ann. Geophys., 19, 395-409, 2001, http://www.ann-geophys.net/19/395/2001/

Akhoondzadeh, M., Parrot, M., and Saradjian, M. R.: Electron and ion density variations before strong earthquakes $(M>6.0)$ using DEMETER and GPS data, Nat. Hazards Earth Syst. Sci., 10, $7-$ 18, doi:10.5194/nhess-10-7-2010, 2010.

Antsilevich, M. G.: The influence of Tashkent earthquake $n$ the Earth's magnetic field and the ionosphere, Tashkent earthquake 26 April 1966, Tashkent, FAN, 187-188, 1971.

Bilitza, D., Obrou, O. K., Adeniyi, J. O., and Oladipo, O.: Variability of foF2 in the equatorial ionosphere, Adv. Space Res., 34, 1901-1906, 2004.

Dabas, R. S., Das, R. M., Sharma, K., and Pilai, K. G. M.: Ionospheric pre-cursors observed over low latitudes during some of the recent major earthquakes, J. Atmos. Sol.-Terr. Phy., 69, 1813-1824, 2007.

Datchenko, E. A., Ulomov, V. I., and Chernishova, C. P.: Electron density anomalies as the possible precursor of Tashkent earthquake, Dokl. AN Uzbek SSR, 12, 30-32, 1972.

Dobrovolsky, I. R., Zubkov, S. I., and Myachkin, V. I.: Estimation of the size of earthquake preparation zones, Pure Appl. Geophys., 117, 1025-1044, 1979.
Forbes, J. M., Palo, S. E., and Zhang, X.: Variability of the ionosphere, J. Atmos. Sol.-Terr. Phy., 62, 685-693, 2000.

Gokhberg, M. B., Pilipenko, V. A., and Pokhotelov, O. A.: Satellite observation of the electromagnetic radiation above the epicentral region of an imminent earthquake, Dokl. AN SSSR, 268, 56-58, 1983a.

Gokhberg, M. B., Pilipenko, V. A., and Pokhotelov, O. A.: On seismic precursors in the ionosphere, Izv. AN SSSR, Fiz. Zhemli, 10, 17-21, 1983b.

Gokhberg, M. B., Morgonhov, V. A., and Pokhotelov, O. A.: Earthquake Prediction, Seismo-Electromagnetic Phenomena, Gordon and Breach Publishers, 1995.

Gousheva, M., Glavcheva, R., Danov, D., Angelov, P., Hristov, P., Kirov, B., and Georgieva, K.: Satellite monitoring of anomalous effects in the ionosphere probably related to strong earthquakes, Adv. Space Res., 37, 660-665, 2006.

Hao, J., Tang, T., and Li, D.: Progress in the research of atmospheric electric field anomaly as an index for short-impending prediction of earthquakes, J. Earthquake Pred. Res. 8, 241-255, 2000.

Hayakawa, M.: Electromagnetic phenomena related with earthquakes, IEEE Transaction FM, 126(4), 211-214, 2006.

Hobara, Y. and Parrot, M.: Ionospheric perturbations linked to a very powerful seismic event, J. Atmos. Sol.-Terr. Phy., 67, 677685, 2005.

Hsiao, C. C., Liu, J. Y., and Oyama, K. I.: Seismo-ionospheric precursor of the 2008 Mw7.9 Wenchuan earthquake observed by FORMOSAT-3/COSMIC, GPS Solut., doi:10.1007/s10291-0090129-0, 2009.

Kazimirovski, E. S.: Coupling from below as a source of ionospheric variability: a review, Ann. Geophys.-Italy, 40, 1-29, 2002.

Kim, V. P. and Khegai, V. V.: On possible changes in the midlatitude upper ionosphere before strong earthquakes, J. Earthq Predict. Res. 6, 275-280, 1997.

Liu, J. Y., Chuo, Y. J., Pulinets, S. A., Tsai, H. F., and Zeng, X. P. A study on the TEC perturbations prior to the Rei-Li, Chi-Chi and Chia-Yi earthquakes, Seismo elctromagnetics: LithosphereAtmosphere-Ionosphere Coupling, edited by: Hayakawa, M. and Molchanov, O. A., TERRAPUB, Tokyo, 297-301, 2002.

Liu, J. Y., Chuo, Y. J., Shan, S. J., Tsai, Y. B., Chen, Y. I., Pulinets, S.A., and $\mathrm{Yu}$, S.B.: Pre-earthquake ionospheric anomalies registered by continuous GPS TEC measurements, Ann. Geophys., 22, 1585-1593, 2004, http://www.ann-geophys.net/22/1585/2004/.

Liu, J. Y., Chen, S. W., Chen, Y. C., Yen, H.Y., Chang, C.P., Chang, W.Y., Tsai, L.C., Chen C.H., and Yang, W.H.: Seismoionospheric precursors of the 26 December 2006 M 7.0 Pintung earthquake doublet, Terr. Atmos. Ocean. Sci., 22, 1585-1593, 2008.

Molchanov, O. A. and Hayakawa, M.: Subionospheric VLF signal perturbations possibly related to earthquakes, J. Geophys. Res., 103, 17, 489-17, 504, 1998.

Molchanov, O., Fedorov, E., Schekotov, A., Gordeev, E., Chebrov, V., Surkov, V., Rozhnoi, A., Andreevsky, S., Iudin, D., Yunga, S., Lutikov, A., Hayakawa, M., and Biagi, P. F.: Lithosphereatmosphere-ionosphere coupling as governing mechanism for preseismic short-term events in atmosphere and ionosphere, Nat. Hazards Earth Syst. Sci., 4, 757-767, doi:10.5194/nhess-4-7572004, 2004. 
Namgaladze, A. A., Shagimuratov, I. I., Zakharenkova, I. E., Zolotov, O. V., and Martynenko, O. V.: Possible mechanism of the TEC enhancements observed before earthquakes. XXIV IUGG General Assembly, Perugia, Italy, 02-13 July 2007, 2007.

Ondoh, T.: Investigation of precursory phenomena in the ionosphere, atmosphere and groundwater before large earthquakes of M > 6.5, Adv. Space Res., 43, 214-223, 2009.

Otsuka, Y., Ogawa, T., Saito, A., Tsugawa, T., Fukao, S., and Miyazaki, S.: A new technique for mapping the total electron content using GPS network in Japan, Earth Planets Space, 54, 63-70, 2002.

Pulinets, S. A., Legen'ka, A. D., and Alekeseev, V. A.: Preearthquake ionospheric effects and their possible mechanisms, in Dusty and Dirty Plasmas, Noise and Chaos in Space and in Laboratory, Plenum Publishing, New York, 545-557, 1994.

Pulinets, S. A. and Legen'ka, A. D.: Dynamics and the nearequatorial ionosphere perior to strong earhquakes, Geomagn Aeronomy, 42(1), 227-232, 2002.

Pulinets, S. A. and Boyarchuk, K. A.: Ionospheric Precursors of Earthquakes, Springer Verlag Publ., 131-171, 2004.

Plotkin, V. V.: GPS detection of ionospheric perturbation before the 13 February 2001, El Salvador earthquake, Nat. Hazards Earth Syst. Sci., 3, 249-253, doi:10.5194/nhess-3-249-2003, 2003.

Rapoport, Yu, G., Gotynyan, O. E., Ivchenko, V. M., Kozak, L. V., and Parrot, M.: Efect of acoustic-gravity wave of the lithospheric origin on the ionospheric $\mathrm{F}$ region before earthquakes, Phys. Chem. Earth, 29, 607-616, 2004.

Rishbeth, H. and Mendillo, M.: Patterns of F2-layer variability, J. Atmos. Sol.-Terr. Phy., 63, 1661-1680, 2001.

Ruzhin, Yu, Y., Larkina, V. I., and Depueva, A. K.: Earthquake precursors in magnetically conjugated ionosphere regions, Adv. Space Res., 21(3), 525-528, 1998.

Shalimov, S. and Gokhberg, M.: Lithosphere-ionosphere coupling mechanism and its application to the earthquake in Iran on June 20, 1990, A review of ionospheric measurements and basic assumptions, Phys. Earth Planet. In., 105, 211-218, 1998.

Sarkar, S., Gwal, A. K., and Parrot, M.: Ionospheric variations observed by the DEMETER satellite in the mid-latitude region during strong earthquakes, J. Atmos. Sol.-Terr. Phy., 69,1524-1540, 2007.

Sahai, Y., Fagundes, P. R., and Bittencourt, J. A.: Solar cycle effects on large scale equatorial F-region plasma depletions, Adv. Space Res., 24(11), 1477-1480, 1999.
Saroso, S., Liu, J. Y., Hattori, K., and Chen, C. H.: Ionospheric GPS TEC Anomalies and $M \geq 5.9$ Earthquakes in Indonesia during 1993-2002, Terr. Atmos. Ocean. Sci., 19(5), 481-488, doi:0.3319/TAO.2008.19.5.481(T), 2008.

Sorokin, V. M. and Chmyrev, V. M.: Modification of the ionosphere by seismic related electric field, in: Atmospheric and ionospheric electromagnetic phenomena associated with earthquakes, edited by: Hayakawa, M., Terra Scientifc Publishing Company (TERRAPUB), Tokyo, 805-818,1999.

Trigunait, A., Parrot, M., Pulinets, S., and Li, F.: Variations of the ionospheric electron density during the Bhuj seismic event, Ann. Geophys., 22, 4123-4131, 2004, http://www.ann-geophys.net/22/4123/2004/.

Vershinin, E. F., Buzevich, A. V., Yumoto, K., Saita, K., and Tanaka, Y.: Correlations of seismic avtivity with electromagnetic emissions and variations in Kamchatka region, in: Atmospheric and electromagnetic phenomena associated with earthquakes, edited by: Hayakawa, M., Terra Scientific Publishing Company, Tokyo, 513-517, 1999.

Warnant, R. and Pottiaux, E.: The increase of the ionospheric activity as measured by GPS, Earth Planets Space, 52, 1055-1060, 2000.

Yiyan, Z., Yun, W., Xuejun Q., and Xunxie, Z.: Ionospheric anomalies detected by ground-based GPS before the Mw7.9 Wenchuan earthquake of May 12, 2008, China, J. Atmos. Sol.-Terr. Phy., 71,959-966, 2009.

Zakharenkova, I. E., Krankowski, A., and Shagimuratov, I. I.: Modification of the low-latitude ionosphere before the 26 December 2004 Indonesian earthquake, Nat. Hazards Earth Syst. Sci., 6, 817-823, doi:10.5194/nhess-6-817-2006, 2006.

Zakharenkova, I. E., Shagimuratov, I. I., Krankowski, A., and Lagovsky, A. F.: Precursory phenomenon observed in the total electron content measurements before great Hokkaido of September 25, 2003 (M=8.3), Stud. Geophys. Geod., 51, 267278, 2007.

Zakharenkova, I. E., Shagimuratov, I. I., Tepenitzina, Yu, N., and Krankowski, A.: Anomalous modification of the ionospheric total electron content prior to the 26 September 2005 Peru earthquake, J. Atmos. Sol.-Terr. Phy., 70, 1919-1928, 2008.

Zainol Abidin, A. R., Momani, M. A., Sulaiman, S., Mohd Ali, M. A., Yatim, B., Fraser, G., and Sato, N.: GPS ionospheric TEC measurement during the 23rd November 2003 total solar eclipse at Scott Base Antarctica, J. Atmos. Sol.-Terr. Phy., 68, 12191236, 2006. 